\title{
Bidding for Success? Impacts of the European Capital of Culture Bid
}

\author{
GREG RICHARDS ${ }^{\mathrm{a}, \mathrm{b}}$ (1) and LÉNIA MARQUES
}

a Tilburg University, Netherlands; ${ }^{b}$ NHTV Breda University of Applied Sciences, Netherlands; 'Bournemouth University, UK

\begin{abstract}
The increasingly multifaceted nature of event impacts makes them even more attractive as a potential solution to a range of urban and regional problems. As a result, competition to stage major cultural and sporting events is intensifying, and the cost of bidding is also rising. Given that such bidding processes only produce one winner, this means that a growing number of disappointed cities have to justify the costs of bidding for major events. In this context, we analyse the bidding process for the European Capital of Culture in the Netherlands (2018) and its impacts on local social structures. In particular the article focuses on the less tangible, non-economic effects of bidding for events, establishing a framework based on network formation, public support for the bidding process and social cohesion. The conclusions point to the key role of sociality and networking for events, which should therefore be developed throughout the bidding process for successful impacts, whether the event is won or not.
\end{abstract}

\section{KEY WORDS}

Events bidding; soft impacts; European Capital of Culture; networks; social cohesion

\section{Introduction}

As cities and regions are exposed to the competitive pressures generated by growing globalisation of economic, social and cultural processes, they increasingly try to position themselves in global fields to attract resources, talent and attention. Arguably, events are a suitable medium for supporting such positioning strategies, as they can have an impact on the economic capacity of places as well as attracting media attention, adding to the liveliness of places and increasing local pride and social cohesion (Jago, Chalip, Brown, Mules, \& Ali, 2003; Kraft, 2008; Richards, de Brito, \& Wilks, 2013). Major events are therefore often seen as a potential solution to a raft of problems, such as urban regeneration, image creation, social cohesion, network building and attraction of talent.

Not surprisingly, therefore, the struggle to attract major events, which are often awarded via a bidding process, has become ever fiercer. For example, Jones (2001) and Westerbeek, Turner, and Ingerson (2002) point out the high cost of bidding for major sporting events such as the Olympic Games or the Rugby World Cup. The number of cities bidding for cultural events such as the European Capital of Culture (ECOC) has also increased significantly. For the 2016 title, for example, there were 16 cities bidding from Spain and 11 from Poland (Palmer, Richards, \& Dodd, 2012). 
One of the major reasons for this rush to attract events has been the idea that they can generate considerable economic impact. For example, bidding for the London Olympic Games was forecast to cost $£ 13$ million in 2002, against potential net benefits of $£ 350$ $£ 680$ million in economic terms, plus a wide range of other benefits in terms of tourism growth, image enhancement and urban regeneration (ARUP, 2002). Having eventually won the event, London was reported to have benefitted from "at least $£ 28$ billion of economic impact", created through the construction and staging of the Games along with tourism, trade and inward investment (DCMS, 2013).

According to ARUP (2002), the strategy for bidding for the London Olympic Games would always generate a positive outcome, given that both scenarios for winning and losing the title would be strategically considered in the Olympics Masterplan:

Should London bid for the Games but be unsuccessful in securing the nomination, there are still significant non-quantifiable benefits to be gained from deciding to bid. The most important benefit will be the potentially catalytic impact on the regeneration of the Lower Lee Valley, by facilitating the assembly of sites and allowing a strategic approach to redevelopment within the area. Regeneration benefits to the area during the bidding phase can be realised through careful planning during the further development of the Olympic masterplan so that an alternative bidding and losing masterplan is developed and is an integral part of the Olympic proposal. Irrespective of whether it is successful or not, a well-managed bid would also have the potential to deliver prestige and promotion benefits both to East London and to the UK as a whole. (pp. 10-11)

As the post-event impact assessment indicated, the effects of winning are always likely to be much greater than if a bid is unsuccessful, but the implication is that even an unsuccessful bid is likely to have positive effects.

However, the difficulties and risks are increasing in the race to stage such events, due to the growing cost of the bidding process itself (Richards, 2015). London eventually spent around $£ 15.2$ million on its successful 2012 bid, and "reports suggest that Chicago spent close to $\$ 80$ million on its unsuccessful bid for the 2016 Games" (Burton \& O'Reilly, 2012).

Similar bid inflation seems to be taking place in the ECOC event. In the case of the $E C O C$, estimated economic impacts of the cultural programme range from around $€ 40$ million (Bruges 2002) to $€ 1$ billion (Liverpool 2008). The expected economic, cultural and social benefits of the ECOC have stimulated growing numbers of cities to bid for the event, with bidding costs increasing from almost zero (with political lobbying being the most important tool) to several million euros (see Table 1).

The bidding process for a major event can also take many years, and there is a considerable lag between launching a bid and the eventual benefits that may accrue from the event. In the case of Cordoba, for example, the city began its bid for the 2016 ECOC in

Table 1. Netherlands 2018 - candidate city budgets in the bidding phase (2010-2013).

\begin{tabular}{lr}
\hline Utrecht & $€ 1.2$ million \\
\hline The Hague & $€ 2.0$ million \\
Maastricht (to 2014) & $€ 7.0$ million \\
Leeuwarden (Friesland) & $€ 1.2$ million \\
Eindhoven-Brabant & $€ 4.5$ million \\
Average budget & $€ 3.2$ million \\
\hline
\end{tabular}

Source: Richards et al. (2012). 
Spain in 2001. In the case of Madrid's Olympic bids, the city has only finally thrown in the towel after three unsuccessful bidding rounds spanning eight years.

With increasing competition for events and also with the accompanying increase in the costs and risks of the bidding process, and given that only one city can eventually win, there is also pressure on bidders to show that the bidding process itself has a positive effect, even if the bid itself is not successful. There are some indications that unsuccessful bids can also have positive impacts. For example, a recent report indicated that the whole Olympic candidacy process had generated over $€ 9$ billion in economic benefits for Madrid, in spite of the successive negative outcomes (Observatorio Económico de Madrid, 2013). However, this estimate was based mainly on the investment in sports facilities, and does not take into account the opportunity costs of these investments. More general econometric studies (Rose \& Spiegel, 2011) have also indicated that the process of Olympic bidding tends to increase economic growth in cities. When Newcastle-Gateshead bid for the UK ECOC for 2008, they were widely seen as the favourites for the title, but they lost out to eventual winners Liverpool. Rather than simply licking their wounds, Newcastle-Gateshead instead invested in another cultural events programme, at least partially rationalised by the argument that the ECOC bidding process had delivered $£ 24$ million worth of economic impact for an investment of around $£ 6.5$ million (Richards \& Palmer, 2010).

It is notable that most studies pertaining to impacts focus on economic effects, which are driven by the considerable economic costs and potential benefits of the bidding process. In contrast, there is very little research on the less tangible cultural, social and image effects of bidding, even though these are usually among the positive claims made for the bidding process. For example, according to Sanetra-Szeliga (2013), the 10 Polish cities that lost the bid for ECOC 2016 had a significant "change in the paradigm of thinking about the connections between culture and socio-economic development on the city level" (p. 94). However, such claims are usually based on assumptions rather than well-grounded research. Very few bidding cities or regions bother to do research into the impacts of the bidding process, even though this is arguably becoming more important.

The present paper is then a first attempt to evaluate the soft impacts of the bidding process, in terms of network formation and civic support for the bidding process. Given the relative lack of bid research and the specific gap in terms of failed bids, this paper outlines some potential ways forward in measuring the wider impact of bidding, particularly concentrating on the soft impacts of bids, such as networking and social cohesion effects. Within this framework, the bidding process for the ECOC title for 2018 in the Netherlands is considered in more detail, identifying the obstacles to and potential strategies for measuring the effects of bidding for events.

\section{Literature Review}

Even though there is an increasingly sophisticated system of impact measurement associated with the ECOC (Richards, 2015), monitoring and evaluation tend to concentrate on the short-term impacts produced by the event year itself, rather than the whole process from bid to legacy. The focus therefore remains on impacts which are short term, rather than on long-term effects. Most bidding research is also limited to immediate impacts. 
As soon as a decision is made, analysis of the bidding process usually stops. The winning city gets on with the process of organising the event, and sees the bid process as successful because the title has been won. In losing cities research tends to be focussed elsewhere or may stop completely, allowing the effects of bidding to fade from view. The losing cities may engage briefly in recriminations about the way in which the bid was handled or the amount of money that was spent, before getting back to the reality of having to find a Plan $B$ or forgetting about the process altogether.

Any learning process that accrues from the failure of bidding tends to remain restricted to the bid process itself - usually making sure that subsequent bids will be successful. This means that the wider effects of the bid on the political, social or cultural system tend to be ignored. This is also because many eventful cities depend on a liberal dose of myth-making that positions them as being successful (Richards \& Palmer, 2010). Politicians in particular are quick to dissociate themselves from unsuccessful bids, and funding for research is usually quickly withdrawn and the failure quickly forgotten (Nooij \& Van den Berg, 2013).

For these reasons very little attention has been paid to the evaluation of the bid process itself. The only people who might have some passing interest in this subject are academics, but even then their interest seems to centre on a critical view of the effects of urban competition (Richards, 2000; Trono \& Rizello, 2015) or event management (Dwyer, Mellor, Mistilis, \& Mules, 2000; Getz, 2004; Rojek, 2013). There have been a few more detailed studies of the ECOC bidding process, but the main focus of such studies is primarily on the media coverage of the process, which is relatively easy to measure (Garcia, 2005; Roth \& Frank, 2000). One attempt to address a less tangible aspect of bidding was made by Immler and Sakkers (2014), who assessed the "European Dimension" of ECOC bid-books.

While some cities have attempted to model the economic effects of the bidding process in terms of investment in facilities and tourism flows stimulated by image improvement (e.g. Observatorio Económico de Madrid, 2013), the soft effects such as cultural, social and organisational capital changes are harder to measure. This complexity, connected to the fact that bidding is a process, calls for dynamic and flexible tools that can provide an accurate portrait of what is happening at different stages in the process. It is therefore not surprising that this is one of the areas the European Capitals of Culture Policy Group (2010) identifies as requiring further research.

Knowledge of the process and outcomes of bidding is becoming increasingly important as cities compete for a growing number of international events and titles. The problem is that research is either not undertaken in the bidding phase, or else the research process stops as soon as the bid fails. The fact that the bidding process often involves fragmented interests and stakeholders is a further challenge to deal with. In his study based on bidding for conventions, Getz (2004) identified five success criteria: to have strong partners in the bid process; to make excellent presentations to the decision-makers; to treat every bid as a unique process; to promote the track record of the community in hosting events and to assist other organisations to make better bids. These factors, although focussed on the single bidding process, are expanded by contextual elements which are not always tangible and are hardly measurable.

Event bidding can also produce varying effects at the different stages in the process. As ARUP (2002) noted in the case of the London Olympics bid, most of the bidding effects are also intangible. For this reason, some authors such as Garcia (2013) or Sacco and Blessi (2004) refer to the soft effects, such as those related to cultural, social or organisational 
capital. Some of these intangible factors are also part of the framework developed to evaluate the event itself, such as community engagement and legacy (European Capitals of Culture Policy Group, 2010). However, such effects often require new approaches to measurement and monitoring, in particular regarding the bidding process.

\section{Effective Tools for Evaluation}

There have been some studies of cultural events, namely the ECOC, which take the soft effects into account and use different methods such as narrative analysis or experimental approaches (e.g. Kania, 2013). In research related to the impacts of major events such as the ECOC, there have been therefore growing calls for more holistic measurement strategies (Richards, 2014, 2015). Arguably, the use of a diverse range of quantitative and qualitative research methods will contribute to capturing improved data about potential impacts. There is also a need to develop longitudinal research in order to analyse the changing dynamics of the bidding process itself.

In constructing a monitoring and evaluation programme for events and event bidding processes, it is important to identify the areas of research focus as well as the appropriate research methods to employ. In terms of the focus of research, Palmer (2004) in his extensive study of different ECOCs used a set of dimensions from which we can extract a number of broad areas for evaluation of impacts: organisation and delivery; aims and objectives; cultural impact; marketing and communication; economic impact; visitors impact; social impacts; legacy and long-term effects (which include social, economic and cultural aspects). These were later extended by Impacts08 to include indicators such as cultural access; participation in cultural activities/life; economy; tourism; cultural vibrancy/atmosphere; sustainability; image; perception of the city; governance and delivery process /effectiveness in executing the process (Garcia, Melville, \& Cox, 2009).

Recent studies have therefore tended to include more elements of intangible cultural, social and image impacts. For example, Richards et al. (2013) present a collection of different cases focussed on the social impact of events. This volume includes a study on ECOC bidding processes in Maastricht (Evans \& van Heur, 2013), an experimental approach to social measurement in Brabant (Kania, 2013), a survey of levels of identification with Brabant as a result of the ECOC bid (Verhoven, 2013) and a multiannual cultural programme in the city of Den Bosch in the Netherlands, where the soft effects of the programme are currently being monitored (Marques, 2013). Richards and Rotariu (2015) also report on the results of a long-term ECOC monitoring process, which underlines the importance of social cohesion, leadership and networking as success factors.

There has been extensive development of case study approaches, although these have predictably concentrated on the more successful events, such as Glasgow 1990 (Garcia, 2005) or Liverpool 2008 (Garcia et al., 2009). However, even the relatively comprehensive Impacts08 approach tends to focus overly on the event, ignoring the broader potential effects on the urban system, and it is also lacking in a sound theoretical basis (Richards, 2015). An interesting alternative approach is that developed by Sacco and Blessi (2007), which is firmly grounded in economic and social theory, and which also considers a wide range of different effects beyond the event itself. These were the major reasons 
for selecting this framework as the basis for a monitoring and evaluation system developed for the bidding process for the 2018 ECOC competition by BrabantStad, a network city composed of five cities in the Dutch Province of North Brabant and which was led by the city of Eindhoven.

\section{Constructing an Alternative Approach to Event Evaluation}

Most event evaluation is undertaken on the basis of measuring the impacts, or immediate outputs of events. However, as the economists Sacco and Blessi $(2004,2007)$ have argued, a measurement of impacts only considers limited aspects of the urban system, and does not take into account the longer term growth of different forms of capital in the urban system as a whole. In addition, the selection of impact measures is not based on any theoretical knowledge of the functioning of the urban system, but rather on an inductive assessment of the areas most likely to be impacted by the event. The analysis developed by Sacco and Blessi, therefore, started from the theoretical premise that urban and regional systems need to improve a range of different processes and accumulate different forms of capital (e.g. physical, human, social, symbolic and natural) in order to be successful.

The framework developed by Sacco and Blessi to evaluate the effects of the ECOC is specifically based on the relationship between culture and local development. They identify a "progressive cultural district" model, which is underpinned by three basic research lines (Sacco \& Blessi, 2007, p. 118):

- the creativity-based attraction model of Florida (2002), which emphasises the role of quality of life and of technological infrastructure in the creation of a critical mass for the emergence of a knowledge-oriented economy;

- the competitiveness-based urban renovation model of Porter (1989), which focuses upon the transition from an investment-based industrial orientation towards a self-sustaining innovation-based economy;

- the capability-based model of Amartya Sen (1992, 1999), which underlines the central role of a general social involvement in capability-building activities as a prerequisite for viable economic development.

The combination of these three approaches, they argue, provides an overview of the key variables that affect the performance of the cultural system. These can be grouped into five main areas:

- Development (development of local entrepreneurship and development of local talent);

- Attraction (attraction of external firms/capitals, attraction of external talent);

- Quality (quality of cultural supply, quality of local governance and quality of the production of knowledge);

- Sociality (management of social criticalities and marginality, capability building and education of the local community, participation and involvement of the local community);

- Networking (internal networking and external networking). 
The Development and Attraction dimensions can be assessed largely in terms of quantitative indicators, and these equate closely with the current focus of much event impact research. These dimensions include the direct and indirect economic effects of events, as well as the indirect economic effects such as image improvement, which arguably increases the attractiveness of cities. However, the Quality, Sociality and Networking dimensions go beyond the normal scope of most event impact assessment, dealing mainly with intangible, soft factors of development.

This framework is useful because it extends the range of event effects considered, providing a strong link with theories of urban development, and concentrating on the longer term effects of events rather than on their immediate impacts. For these reasons the framework was also selected as the basis for the monitoring and evaluation programme for the BrabantStad 2018 bid for the ECOC in the Netherlands (Richards, 2013). The following sections outline the methods used, the background to the bid as well as the application of the framework to the BrabantStad case.

\section{Methodology}

The monitoring of the effects of the bidding process for BrabantStad was based on the progressive cultural district model of Sacco and Blessi (2004), outlined above. The study adopted a mixed-methods approach in order to gather data related to the different dimensions of the model (van Bommel, du Long, Luijten, \& Richards, 2011).

In the first phase of the research, a baseline study of BrabantStad was conducted by Tilburg University and PON (a research organisation of the Province of North Brabant) in 2010 and 2011. The baseline study was designed to provide a pre-event measure of the different aspects of culture in North Brabant, so that subsequent changes related to the ECOC event could later be assessed.

\section{Research Model}

Because considerable data gathering was already taking place on cultural production and participation as part of the normal research programme of the Province, it was decided to concentrate the first phase of the study on the Sociality and Networking dimensions of the bid process itself. As outlined above, these are aspects of event effects that are often overlooked. In the baseline study the following aspects of Sociality and Networking were measured:

(1) Gauging the opinions of residents in the Province of Brabant, residents in other parts of the Netherlands and entrepreneurs in Brabant concerning BrabantStad and its candidacy for the ECOC 2018 (Sociality dimension).

(2) Analysing (existing or new) networks initiated or inspired by BrabantStad's candidacy (Networking dimension).

Based on the theoretical framework developed for the ECOC by Sacco and Blessi (2004) as a foundation, the dimensions of sociality and networking were operationalised in the baseline study of BrabantStad as follows: 


\section{Sociality}

- Skills, competences and training of the local community and cultural education;

- Participation in voluntary associations;

- Local pride, appreciation of own city and awareness of BrabantStad.

\section{Networking}

- Networking between cultural organisations, entrepreneurs and municipalities in Brabant;

- External networking between cultural organisations, entrepreneurs and municipalities outside Brabant.

A number of methods were employed in the assessment of these dimensions. These included the following:

- Surveys of residents and non-residents of North Brabant;

- Survey of cultural enterprises in North Brabant and the Netherlands as a whole;

- In-depth interviews with key stakeholders regarding networking processes;

- Focus groups with cultural sector representatives.

In order to provide longitudinal measures related to the bidding process, the surveys were distributed to existing panels of respondents at regional and national levels at different moments during the bidding process. Stakeholder interviews were also undertaken during two separate time periods in the bid phase.

In the current study two particularly important elements of the soft impact of the bidding process will be analysed: the development of cultural networks as a consequence of the bid, and the generation of social cohesion and identification among citizens of Brabant as a result of the bid. The development of cultural networks is a particularly important indicator for the Networking dimension of the Sacco and Blessi (2004) framework, and social cohesion was a particularly important desired outcome of the bid, which relates to the Sociality dimension of the framework.

The intention was to cover all of these areas over the course of the bid and the development of the ECOC event itself. However, because BrabantStad was finally not selected as ECOC, only the first phase of this study was completed. Since the failure of the bid, however, the authors have continued monitoring the situation in BrabantStad, in particular among key stakeholders, to measure the effect of the failed bid.

\section{Data Collection}

The networking dimension was qualitatively examined through in-depth interviews held in October 2010 and November 2011 with 30 cultural institutions in North Brabant, including museums, theatres, music venues and cultural entrepreneurs. In addition, surveys of cultural organisations were carried out to determine the extent of networking, collaboration and involvement with the BrabantStad bid. These were distributed in October 
2010 and again in June 2011 (109 responses), just before the submission of the first round bid document. Resident surveys were undertaken through the Brabant Panel (1500 respondents), the Resident Panels of the five cities involved in the bid ( 2500 respondents). Non-resident consumers were asked their views on the bid via the representative national panel of a major market research company (5000 respondents) in 2011 . A second round of surveys was undertaken with residents and non-residents in the period just prior to the selection decision via the Leisure Panel of Tilburg University (www.leisurepanel.eu). The samples for the different panels are comparable in terms of composition and representation of the regional/national population.

In addition to the large-scale quantitative and qualitative studies, smaller and more focussed studies were conducted on the identification of local residents with the region and the bid process (Verhoeven, 2013) and social cohesion and social capital (Kania, 2013). A set of in-depth interviews with museums was also conducted in 2013, just before the decision to award the title was announced.

The survey data were analysed using SPSS and the qualitative data from the interviews and focus groups were transcribed and coded for subsequent analysis. The data from the different elements of the research were triangulated to identify patterns and (in)consistencies in the data. The use of a mixed-methods approach allowed us to provide a quantitative and directly comparable indication of the level of support for the bid, civic engagement and cultural network involvement, as well as giving deeper insights into issues such as social cohesion, connections between actors, collaboration and other soft impacts of sociality and networking.

\section{The Bidding Process for BrabantStad 2018}

In 2018, together with Malta, the Netherlands will host the ECOC. In contrast to Malta's capital Valetta, which was unanimously nominated to represent the whole country, the selection process in the Netherlands was organised as an open competition. In September 2013, Leeuwarden was awarded the title, Utrecht and The Hague having already been eliminated in the first round of the competition (Richards, 2015) and BrabantStad and Maastricht having been beaten in the final round. The bidding process lasted several years and the investment of each city in the process was over $€ 3$ million on average (see Table 1).

Such large investments in bidding, which come mainly from the public sector, increase the pressure on politicians to justify the investment of public money being used, and to outline what the benefits will be (Nooij \& Van den Berg, 2013). One might perhaps also ask if it is sensible that, in the Dutch case, around $€ 19$ million was invested in bidding for an event with an estimated total budget of between $€ 40$ million and $€ 80$ million. The justification for investing so much in a bidding process goes beyond the principle of giving cities an equal chance of getting the title. Bidding for events is often seen as a strategic tool for cities, allowing them to develop towards the aims stated in the bid (Getz, 2004). For example, the three final cities in the race for the Dutch ECOC 2018 title had economic and regional development aims (Leeuwarden), social cohesion and social innovation aspirations (BrabantStad), or were seeking to reinforce their European identity and international cooperation (Maastricht). The cities tended to argue that even if the bid 
were not successful, the bidding process itself would help them to work towards these goals (Evans \& van Heur, 2013).

However, in a long-running bidding process, it is also important to convince a wide range of stakeholders of the utility of the bid. Throughout the way and since the first steps till the implementing of the project, stakeholder expectation management is an important factor to take into account as Åkerlund and Müller (2012) point out for Umeå, in Sweden. Among the key stakeholders, the involvement of citizens is deemed to be increasingly important for high-impact events, such as the Olympics or the ECOC. Since the bidding process in the Netherlands started more than eight years before the event itself, the continued involvement of citizens in the bidding and implementation process is vital for the success of the programme. All of the candidate cities therefore attempted to develop civic involvement in the programme, as for example Kania (2013) describes in the case of BrabantStad, which organised events specifically aimed at awareness raising of and local involvement in the bidding process. This also became part of the BrabantStad evaluation process, as the organisers were concerned to know the levels of public support for the bid, and to use this as an argument for the candidacy. The evaluation programme for BrabantStad, therefore, started in the bidding phase, and it was arguably the most comprehensive research conducted to date on the effects of ECOC bidding (van Bommel et al., 2011).

In the bidding stages of the BrabantStad programme (2018 Eindhoven/Brabant, 2013), it was felt important to concentrate the research particularly on processes of coalition building and network forming (the Networking dimension of the model), since as pointed out by different studies, these would be the "sticky" element of the bid, on the one side, and a key success factor for its potential implementation on the other side (Åkerlund \& Müller, 2012; Getz, 2004). In the case of BrabantStad, these processes were particularly important because the bid was based on a network of five cities (Breda, Eindhoven, Den Bosch, Helmond and Tilburg) and the Province of North Brabant to form a "mosaic metropolis". The research question posed by the Province for the evaluation of the bid, therefore, concentrated not only on the effects of the programme itself, but also on the contribution of bidding to network building (van Bommel et al., 2011).

It is interesting to note that the study refers to effects rather than impacts. It is not so important to measure what impact the bid may have had in terms of, for example, increased tourism spending by attracting visitors to the region, but rather how the bid has helped to develop the new cultural and social processes necessary to allow the region to maximise its potential in the longer term.

\section{Findings and Discussion}

From the data gathered during the bid preparation, two aspects emerge as central. The first one is the importance of the internal and external networks, which confirms some conclusions of previous studies in other type of events (Getz, 2004) or in a successful bid (Åkerlund \& Müller, 2012). The second one relates to the community, in which the civic engagement from the beginning of the project on is a key aspect for the success of the ECOC bid. The findings of the research relating to networking and sociality are described in the following sections of the paper. 


\section{Networking}

In the BrabantStad case, it appears that there was relatively little networking taking place outside the immediate geographical location or cultural sector of the cultural organisations in the early stages of bidding. There was a significant growth in networking activity during the development of the bid as cultural organisations began to orientate themselves towards the potential ECOC and to seek each other out as potential project partners. This was specifically driven by the structure of the call for projects, which emphasised projects that included partners from different parts of BrabantStad. The early phases of network building also saw a large amount of cross-sectoral networking, with organisations from different cultural sectors coming together to develop project ideas for the ECOC. This activity also took place against a backdrop of considerable uncertainty in the cultural sector as a whole, with budgets being slashed as a result of the economic crisis, and cultural organisations being forced to seek new sources of funding. This added to the willingness of cultural organisations to get involved in networks around the ECOC.

Interviews held with museums before the final selection decision in 2013 show that initially they were also enthusiastic about the candidacy for the ECOC, not only because of the possibilities that the title would give to the development of culture and cultural projects in the region, but also because of the new projects that were emerging from the exchanges and cooperation during the bidding phase. Despite this general growth in networking, closer to the final selection phase, some of the museums became more sceptical about the bid. This scepticism was less related to the ECOC itself or the prospect of obtaining the title, but was more related to the organisation of the bidding process. Some museums indicated that they no longer felt involved in the bidding process, which they felt had taken a more political direction. Some museums also indicated they were waiting for the selection result to be known before committing themselves to participation. After the title was awarded to Leeuwarden, other issues surfaced, such as the apparent poor communication between the organising committee and the museum network. Despite this, the intention of the museums was mainly to continue with the projects and plans made during the bidding process. However, most museums anticipated that the lack of ECOC funding would mean a slowdown in the pace of network and project development.

The main reasons given by cultural organisations for participating in the ECOC bid were related to "promotion", "marketing" and "getting known". These motivations mirror the findings of Getz (2004) about convention bidding. However a clear difference, regarding the scope of the ECOC project itself, relates to the expressed desire of stakeholders to reinforce their image, especially within Europe. Looking more closely at Sacco and Blessi's framework, both the internal and external dimensions of networking are deemed important. The surveys showed that cultural organisations belonged to an average of eight networks and that these networks were mostly cross-sectoral (involving different cultural sectors). Those networks that were directly involved in the bidding process also tended to be more diverse, indicating that the bid had stimulated more cross-sectoral networking between cultural stakeholders. The ECOC candidacy therefore stimulated the creation of new networks as well as encouraging the growth of pre-existing networks. 
Our analysis also indicates that networking has a spillover effect into other dimensions of the progressive cultural district framework, such as not only development (involving entrepreneurs, for example) but also attraction (with a new positioning, place marketing and also more visitors), which in turn can help to feed the quality perception of the cultural offer. This cannot be done without a high level of support from local citizens, who are also important as both producers and consumers of local culture.

\section{Sociality}

One important criterion for the ECOC competition is that the bidding cities should be able to demonstrate that their bid has the support of citizens. This factor is not only a formal requirement of the bidding process, but it is also widely quoted as being an important success factor in the ECOC event as a whole (Richards \& Palmer, 2010). In some cases, as for example in Umeå (ECOC in 2014), instilling the idea of co-creation with citizens from the bidding phase onwards was an essential factor for the success of the ECOC (Åkerlund \& Müller, 2012).

Many bidding cities, therefore, make great efforts to involve local people in the bidding process, organising promotional campaigns and events and stimulating people to submit projects and ideas for the programme. In the case of BrabantStad, these measures were also designed to stimulate a greater degree of identification with Brabant as a region and BrabantStad as a new network metropolis. The idea behind the bid would, therefore, cover different aspects of the five dimensions of Sacco and Blessi (2004), in particular Sociality (such as pride of the region or participation in local cultural life) and Attraction, which would be supported by the image and experience of the region. However, the results of our research point to gaps and weaker elements in these dimensions.

Surveys of local residents held in 2011 and 2013 indicated the development of awareness of and support for the bid. In 2011 just over half (53\%) of the residents of Brabant were aware of the candidacy of BrabantStad for the ECOC. Just over $40 \%$ also thought the candidacy was a good idea. By 2013, just ahead of the announcement of the result of the bidding process, there had been a marked change in attitudes among local residents. Although more people were aware of the candidacy (not surprisingly, given the promotional campaign and media coverage surrounding it), the proportion of people thinking this was a good idea had fallen from $41 \%$ to only $25 \%$. The willingness of residents to become actively involved in the ECOC programme also fell sharply, from $60 \%$ in 2011 to $40 \%$ in 2013. The trend towards declining support for the bid was also indicated by a poll of 2300 Brabant residents the day before the final selection in September 2013. This indicated that only $37 \%$ of residents thought the bid was a "good thing", and less than a quarter thought that Brabant would actually win the title (compared with $39 \%$ of Friesland residents who thought that their regional capital Leeuwarden would win) (Lubber, 2013).

The lack of support for the bid does not seem to be related to levels of identification with Brabant, but rather with the bid itself. Surveys of almost 300 residents of Brabant in 2011 (Verhoven, 2013) indicated that most residents felt themselves to be strongly connected to the Province of North Brabant; however, it showed that links to the abstract entity of BrabantStad were much weaker. Even though almost $80 \%$ of the respondents were aware of the bid, only $24 \%$ identified themselves with BrabantStad, compared 
with almost 80\% who proudly identified with Brabant in the baseline research in 2011 (van Bommel et al., 2011). This indicates that although there was a high level of identification with the region, this did not extend to the new network metropolis envisaged for the ECOC.

The study by Kania (2013) suggests that the ECOC candidacy event "Together at the Table" had a measurable effect on citizens' attitudes towards the bid process. Those who participated in the event, which consisted of a shared meal specifically designed to stimulate discussions about Brabant and the BrabantStad bid among residents, had a measureable effect on the positive attitudes to BrabantStad compared with a control group. This research indicates that activities such as "Together at the Table" organised to support the BrabantStad candidacy did have a positive effect on local residents, making residents more positive about the bid, and therefore more likely to actively participate in the event of a successful bid outcome.

From the perspective of the Sociality dimension of Sacco and Blessi's framework, therefore, BrabantStad displayed considerable weaknesses. Although the bid was able to mobilise support from citizens in the early phase, enthusiasm waned as the bid progressed, and the bidding team, thinking that local support was assured, turned their attention increasingly towards other stakeholder groups. Although small-scale projects such as "Together at Table" were good at creating social cohesion around the idea of the bid, these were not large scale enough to affect the majority of the local population.

\section{Conclusions}

The results of our research indicate that new insights can be gained from analysing the soft elements of the event bidding process. Although previous studies have outlined the economic benefits that can be gained, even from unsuccessful bids, such as for the Olympic Games, our research indicates that unsuccessful bids may also have wider-reaching effects, even if these are not as clear-cut as many policy-makers might wish.

In terms of the Sacco and Blessi (2004) framework, it appears that there are identifiable Sociality and Networking effects of the BrabantStad bid, particularly in the early phases of the bidding process. This was supported by a considerable investment in the bid itself, with extensive lobbying and networking activities by the organising body. The initial efforts at network building and stimulating local support for the bid appear to have been successful, with a growth in networking in the cultural sector and considerable support evident among most sectors of the local population. Our follow-up research, however, indicates that both networking and local support declined once the initial investment in consensus-building diminished and the organisers turned their attention to political issues arising from the bidding process itself. This is in some sense predictable, because the organising body has many different tasks, and needs to concentrate on different aspects of the bidding process if it is to be successful. Maintaining the balance between different stakeholders is therefore difficult. In the case of BrabantStad, however, this probably proved fatal, because one of the major criticisms from the jury was that the bid did not seem to be developed in a bottom-up fashion with the involvement of local people or the wider cultural sector (European Capital of Culture, 2013).

There are some indications that the bidding process may have a certain halo effect that lasts beyond the bid period itself, even in the case of an unsuccessful bid. This is 
particularly noticeable in the case of Networking, where cultural operators indicated that they were likely to continue the collaborations formed during the bidding process, even if the pace of collaborative work was likely to fall in the absence of funding. It also appears that the new contacts formed during the bidding process are generating new projects and initiatives that are unrelated to the ECOC itself, simply because new links have been formed between potential networking partners. In the case of the Sociality effects of the bid, however, it seems that the halo may sometimes be negative, since falling levels of involvement in and identification with the bid also created dissatisfaction with the project and with policy-makers in general. Concrete evidence of this effect was supplied shortly after the selection result, when considerable media coverage was given to the damage done to the cultural sector in the media (e.g. van Peer, 2013). The discussions about the wider consequences of the failed bid also affected the ability of the Province to implement the smaller scale cultural programme that had been outlined in the bid process as a Plan B in the case of the bid being unsuccessful.

This research shows that there is considerable value in undertaking mixed-methods research and triangulating the results of different studies of the bid process. The quantitative surveys were useful at indicating overall levels of support for the bid and participation in cultural networks, but the qualitative research uncovered a number of nuances, in particular regarding the drivers of networking. In particular, we would argue on the basis of these results that far more attention should be paid to the soft aspects of the ECOC process, such as Sociality and Networking. In the case of BrabantStad these factors appear to have been far more important in determining the dynamics of the bid than hard factors such as economics. Brabant has a significantly stronger economy than the eventual winner, Leeuwarden, and it also scores far higher in terms of talent attraction and retention. Although BrabantStad had a significantly bigger budget than Leeuwarden, it was less effective in using these resources because the levels of identification with the bid were far lower.

This study also has a number of limitations, which represent opportunities to develop future research on the bidding process for events. These include the fact that the official monitoring of the effects of the bidding process stopped as soon as the result of the competition was announced. This means that it is difficult to continue the research in the postbidding phase, even though this is the most crucial period to examine the positive effects of a failed bid. Future research might therefore be designed to cover a fixed period of the bidding process, regardless of the outcome. This might generate useful longitudinal data on the positive and negative effects of event bidding. The current research also focussed on a relatively wealthy region in a relatively wealthy developed country. Future research might also consider the impact of bidding in other contexts, such as poorer regions or emerging economies. Such research would be particularly valuable in a climate in which more and more cities and nations are being drawn into the global event bidding arena.

\section{Acknowledgements}

The authors would like to thank BrabantStad, Eindhoven/Brabant 2018, Frederik Faulseit and Gizem Girgin for their collaboration. 


\section{Disclosure statement}

No potential conflict of interest was reported by the authors.

\section{ORCID}

Lénia Marques (1) http://orcid.org/0000-0002-6360-9919

Greg Richards (I) http://orcid.org/0000-0002-5903-6310

\section{References}

2018 Eindhoven/Brabant (2013). European Capital of Culture bid book. Eindhoven: 2018 Eindhoven/ Brabant.

Åkerlund, U., \& Müller, D. (2012). Implementing tourism events: The discourses of Umeå's Bid for European Capital of Culture 2014. Scandinavian Journal of Hospitality and Tourism, 12(2), 164-180. doi:10.1080/15022250.2011.647418

ARUP (2002). London Olympics 2012: Costs and benefits. Retrieved from http://www.arup.com/_ assets/_download/download368.pdf

van Bommel, M., du Long, K., Luijten, J., \& Richards, G. (2011). BrabantStad's candidacy for European Capital of Culture 2018. Baseline measurement: The principal conclusions. Eindhoven: Eindhoven/ Brabant 2018.

Burton, R., \& O'Reilly, N. (2012, August 20). Soaring cost of Olympic host bids concerns Ueberroth. Sports Business Daily, p. 27. Retrieved from http://www.sportsbusinessdaily.com/Journal/lssues/ 2012/08/20/Opinion/Burton-OReilly.aspx

DCMS. (2013). Post games evaluation: Meta-evaluation of the impacts and legacy of the London 2012 Olympic and paralympic games. London: Department for Culture, Media \& Sport.

Dwyer, L., Mellor, R., Mistilis, N. \& Mules, T. (2000). A framework for assessing "tangible" and "intangible" impacts of events and conventions. Event Management, 6(3), 175-191. doi:10.0000/ 096020197390257

European Capital of Culture. (2013). Selection of the European Capital of Culture 2018 in the Netherlands. The Selection Panel, Final Selection Report. Brussels: European Commission.

European Capitals of Culture Policy Group. (2010). An international framework of good practice in research and delivery of the European Capital of Culture programme. Liverpool: ECoC Policy Group.

Evans, G., \& van Heur, B. (2013). European Capital of Culture - emancipatory practices and Euregional strategies: The case of Maastricht Via 2018. In G. Richards, M. de Brito, \& L. Wilks (Eds.), Exploring the social impact of events (pp. 73-83). London: Routledge.

Florida, R. (2002). The rise of the creative class. New York, NY: Basic Books.

Garcia, B. (2005). Deconstructing the city of culture: The long-term cultural legacies of glasgow 1990. Urban Studies, 42, 841-868. doi:10.1080/00420980500107532

Garcia, B. (2013). London 2012: Cultural olympiad evaluation (final report). Liverpool: Institute of Cultural Capital, University of Liverpool.

Garcia, B., Melville, R., \& Cox, T. (2009). Creating an impact: Liverpool's experience as European Capital of Culture. Liverpool: Impacts08.

Getz, D. (2004). Bidding on events: Critical success factors. Journal of Convention \& Exhibition Management, 5(2), 1-24. doi:10.1300/J143v05n02_01

Immler, N.L. and Sakkers, H. (2014). (Re)Programming Europe: European Capitals of Culture: Rethinking the role of culture. Journal of European Studies, 44(1), 3-29. doi:10.1177/0047244113515567

Jago, L., Chalip, L., Brown, G., Mules, T., \& Ali, S. (2003). Building events into destination branding: Insights from experts. Event Management, 8(1), 3-14.

Jones, C. (2001). Mega-events and host-region impacts: Determining the true worth of the 1999 Rugby world cup. International Journal of Tourism Research, 3(3), 241-251. doi:10.1002/jtr.326

Kania, L. (2013). Social capital in the metropolis BrabantStad. In G. Richards, M. de Brito \& L. Wilks, (Eds), Exploring the social impacts of events (pp. 45-56). London: Routledge. 
Kraft, S. E. (2008). Place-making through mega-events. In J. Ø. Bærenholdt \& B. Granås (Eds), Mobility and place: Enacting Northern European peripheries (pp. 219-231). Aldershot: Ashgate.

Lubber, R. (2013, September 6). Onderzoek Culturele Hoofdstad. De Stem.

Marques, L. (2013). Constructing social landscape through events: The glocal project of 'sHertogenbosch. In G. Richards, M. de Brito, \& L. Wilks (Eds.), Exploring the social impact of events (pp. 84-94). London: Routledge.

Nooij, M. De, \& Van den Berg, (2013). The bidding paradox: Why rational politicians still want to bid for mega sports events (Discussion Paper Series No. 13-09). Tjalling C. Koopmans Research Institute. Retrieved from http://papers.ssrn.com/sol3/papers.cfm?abstract_id=2314350

Observatorio Económico de Madrid. (2013). Effectos derivados del proceso olímpico para la ciudad de Madrid. Barómetro de economía de la ciudad de Madrid, 36(2) Trimestre 2013, pp. 115-135.

Palmer, R. (2004). European cities and capitals of culture: Study prepared for the European commission. Brussels: Palmer/RAE Associates.

Palmer, R., Richards, G., \& Dodd, D. (2012). European cultural capital report, volume 4. Arnhem: ATLAS. van Peer, R. (2013, October 9). Blind door regenteske hoogmoed. Eindhovens Dagblad. Retrieved from http://www.ed.nl/mening/blind-door-regenteske-hoogmoed-1.4042855

Verhoeven, C. A. (2013). Houdoe or Houdios? BrabantStad 2018: European capital of culture and the extent of identification of Brabant's inhabitants. In G. Richards, M. de Brito \& L. Wilks, (Eds.), Exploring the social impacts of events (pp. 57-72). London: Routledge.

Porter, M. E. (1989). The competitive advantage of nations. New York: The Free Press.

Richards, G. (2000). The European cultural capital event: Strategic weapon in the cultural arms race? Journal of Cultural Policy, 6(2), 159-181. doi:10.1080/10286630009358119

Richards, G. (2013). Assessing the return on cultural investment: The case of the European Capital of Culture. Retrieved from http://www.academia.edu/4096364/Assessing_the_return_on_cultural_ investment_the_case_of_the_European_Capital_of_Culture

Richards, G. (2014). Guimarães and Maribor, European Capitals of Culture 2012. Arnhem: ATLAS.

Richards, G. (2015). Evaluating the European Capital of Culture that never was: Brabantstad 2018. Journal of Policy Research in Tourism, Leisure and Events, 7(2), 118-133. doi:10.1080/19407963. 2014.944189

Richards, G., Dodd, D., \& Palmer, R. (2012). European cultural capital report. Arnhem: ATLAS.

Richards, G., de Brito, M., \& Wilks, L. (2013). Exploring the social impact of events. London: Routledge. Richards, G., \& Palmer, R. (2010). Eventful cities: Cultural management and urban revitalisation. London: Routledge.

Richards, G., \& Rotariu, I. (2015). Developing the eventful city in Sibiu, Romania. International Journal of Tourism Cities, 1(2), 89-102.

Rojek, C. (2013). Event power: How global events manage and manipulate. London: Sage.

Rose, A., \& Spiegel, M. (2011). The olympic effect. Economic Journal, 121(553), 652-677. doi:10.1111/j. 1468-0297.2010.02407.x

Roth, S., \& Frank, S. (2000). Festivalization and the media: Weimar, Cultural Capital of Europe 1999. International Journal of Cultural Policy, 6(2), 219-241. doi:10.1080/10286630009358122

Sacco, P., \& Blessi, G.T. (2004). European Culture Capitals and local development strategies: Comparing the Genoa 2004 and Lille 2004 Cases. Retrieved from http://neumann.hec.ca/aimac2005/PDF_Text/ Sacco_TavanoBlessi.pdf

Sacco, P., \& Blessi, G.T. (2007). European Culture Capitals and local development strategies: Comparing the Genoa and Lille 2004 cases. Homo Oeconomicus, 24(1), 111-141.

Sen, A. (1992). Inequality reexamined. Oxford: Oxford University Press.

Sen, A. (1999). Development as freedom. Oxford: Oxford University Press.

Sanetra-Szeliga, J. (2013, October 17-18). Creativity as part of the European Capital of Culture strategies - the case of Poland. The idea of creative city/The urban policy debate, Cracow, Conference proceedings, pp. 94-105.

Trono, A., \& Rizello, K. (2015, May). Culture and event bidding strategies of Lecce city in Southern Italy. Paper presented at the ATLAS Events Group Meeting, Lecce.

Westerbeek, H. M., Turner, P., \& Ingerson, L. (2002). Key success factors in bidding for hallmark sporting events. International Marketing Review, 19(3), 303-322. doi:10.1108/02651330210430712 